Commission can raise the quality of what we have and what we may be able to introduce; the closure of big old psychiatric hospitals releases cash to build alternative services; the emergence of 'Care in the Community' programmes may in time become as important as joint finance in concentrating resources (and minds) on how to provide effective services. But all of that is in danger of being hide-bound, if not still-born, not by attempts to obtain 'value for money'-all governments should encourage that - but by a narrow ideological view of a 'proper' level of public expenditure, regardless of value.

If making mental health services a priority can gain ground, then there are a range of professional interests and more important traditional attitudes which will have to change. Is it not extraordinary that psychiatrists should be paid extra to make domiciliary visits to people when 95 per cent of those suffering from mental illness are not in psychiatric hospitals? To get more psychiatrists to view their base of operation as 'the community' rather than hospitals will take time and accounts for the opposition of some to the proposed closure programme. Nevertheless, without the willing and active support of the majority of psychiatrists, community mental health services will not succeed. Italy shows just such a regional patchwork of keen initiatives and sluggish traditionalism. It is encouraging that housing associations are now much more active and enthusiastic about making provision for mentally ill people. The DoE survey of 1983 showed 622 housing schemes for mentally ill people, and 31 for both mentally handicapped and mentally ill people. The number of mentally ill people so accommodated was 3,300 , and although the majority were in local authority housing, nearly one-third were in housing associations properties.

A greater part in community provision by housing departments and housing associations must be a tradition of the future. Social services departments and their staffs will have to alter attitudes too; or at least accept that a community mental health service cannot be, as it often is at present, a 9-5 pm, 35-hour, five days a week job. Residential staff and some day care staff know this already. All such changes will mean extra costs.

And where is the extra money to come from? It is not only a question of more money, though a reduction of PSS spending will make the whole prospect of new mental health services impossible. There are, as every government knows, inexorable pressures, well documented, from a growing number of very frail, confused elderly people for more health and personal social services. They present a pressing priority; in circumstances where expenditure may decline, their claims will not be ignored. Mental health would be one of the losers. So some relaxation of cash limits is essential. Given the public spending stance of the present government, that relaxation could be quite specific, without 'printing money' or upsetting the economics of the grocery shop. No penalties on schemes for the priority groups which have been joint financed is one small assistance. Better still would be a permanent transfer of joint finance cash from the NHS; the new programme of NHS money from closures may well be bigger than joint finance and establishes a precedent. The exemption from rate penalties of urban aid and inner city partnership cash (which I regret to say my own authority, though well qualified, does not receive), where that is for specific priority service grants, could be made. The use of more specific grant aid for certain services, for example, section 11 from the Home Office, for mental health programmes amongst people of the ethnic minorities and the enlargement of the cash available to housing associations for mental health schemes are both small ways, but of significance in developing some aspects of mental health services.

Above all local and district health authorities require an assured financial framework in which to plan ahead. The agreements about funding which they reach must be guaranteed. It cannot be said that they have experienced the necessary stability in the last four years. So long as insecurity about future central government policies and attitudes continues, so long will mental health policies receive less priority than they deserve. So long too, to the bright hopes of 1983 .

This paper was presented at a meeting of the All Parry Parliamentary Mental Health Group at the House of Commons in May 1984.

\section{European Working Group on Drug Policy Oriented Research}

An international workshop on drug policy oriented research was held for the first time in Rotterdam on 14 and 15 December 1983 organized by the Institute of Preventive and Social Psychiatry of the Erasmus University. At this meeting the participants decided to establish an European Working Group on Drug Policy Oriented Research (EWODOR). This working group will meet once a year; participation is by invitation only and will be limited to research workers.

At the initial meeting some of the topics discussed were the general economy of drugs; the illegal heroin market in The Netherlands; evaluation of the distribution of morphine in Amsterdam; treatment motivation of addicts; and evaluation of treatment in therapeutic communities. The Working Group intends to draw more attention to issues of research in this undervalued field and to stimulate national and international co-operation of researchers. The next meeting will be on 13 and 14 December 1984. Information: Wijnand Sengers, Erasmus University, PO Box 1738, 3000 Rotterdam, The Netherlands.

\section{Disabled Living Foundation}

The Disabled Living Foundation is moving from $346 \mathrm{Ken}$ sington High Street, London W14 8NS to new premises at 380/ 384 Harrow Road, London W9 $2 \mathrm{HU}$ in November/December 1984 (telephone number 01-289 6111). 